\title{
Changing trends in indication of cesarean section in a tertiary care centre of Central India
}

\author{
Pooja Patil $^{1 *}$, Malini Bhardwaj', Priyanka Sharma², Garima Chandrakar ${ }^{1}$
}

\begin{abstract}
${ }^{1}$ Department of Obstetrics and Gynecology, L. N. Medical College, Bhopal, Madhya Pradesh, India
${ }^{2}$ Department of Obstetrics and Gynecology, Sita Devi Hospital, Jaipur, Rajasthan, India
\end{abstract}

Received: 24 May 2017

Accepted: 27 May 2017

\section{*Correspondence:}

Dr. Pooja Patil,

E-mail: pooja_gynec@yahoo.co.in

Copyright: () the author(s), publisher and licensee Medip Academy. This is an open-access article distributed under the terms of the Creative Commons Attribution Non-Commercial License, which permits unrestricted non-commercial use, distribution, and reproduction in any medium, provided the original work is properly cited.

\section{ABSTRACT}

Background: This study was carried out to find the rate of Cesarean section (CS) in our institute from 2012 to 2016 and also to find any change in the indications of CS over these five years.

Methods: A retrospective analysis of data was done from the records of the patients who underwent CS and the rate of Cesarean section and the indications were noticed.

Results: The rate of Cesarean section has increased from $43.85 \%$ in 2012 to $48.18 \%$ in 2016. There is increase in the number of Primary Cesarean cases from $61.8 \%$ in 2012 to $68.4 \%$ in 2016.The percentage of Elective CS has increased in last five years from $10.2 \%$ in 2012 to $23.6 \%$ in 2016 which is due to the drastic increase in Elective Repeat CS from $13.3 \%$ in 2012 to $43.4 \%$ in 2016. The first and second major indication of Primary CS over the years remained the same i.e. fetal distress and CPD. Other major contributing indications were Non-progress of labour, failed induction and Malpresentation. Oligohydraminos and IUGR, Multiple pregnancy and precious pregnancy have emerged as the major indication in last three years. Previous CS and Previous 2 CS contributed as the main indication for Elective CS.

Conclusions: The rate of Cesarean section need to be reduced. The overall main indication for CS was Previous CS and thus Primary CS rate should be reduced. Fetal distress being the main indication for Primary CS should be further confirmed by fetal scalp pH findings and Repeat CS cases should be given more trial of labour.

Keywords: Cesarean section, Emergency, Elective, Indications, Primary CS, Repeat CS

\section{INTRODUCTION}

Cesarean section is the most common major surgical procedure performed in obstetrics. There is increase in the rate of Cesarean section in both developed and developing countries.

Caesarean section, also known as C-section or Caesarean delivery, is the use of surgery to deliver one or more babies. ${ }^{1}$ A caesarean section is often performed when a vaginal delivery would put the baby or mother at risk. ${ }^{1}$
This may include obstructed labour, twin pregnancy, high blood pressure in the mother, breech birth, problems with the placenta, umbilical cord or shape of the pelvis, and previous C-section. ${ }^{1,2}$ A trial of vaginal birth in some of these situations, including after $\mathrm{C}$-section, may be possible. Some C-sections are also performed upon request. ${ }^{1}$ The World Health Organization recommends that they should be done based on medical need and in many cases, they are lifesaving for the mother and baby. ${ }^{2,3}$ There are two types of caesarean sections based on time of operation. They are elective and emergency. 
Elective is when the operation is done at a pre-arranged time during pregnancy to ensure the best quality of obstetric care, anesthesia, neonatal resuscitation and nursing services. Emergency is when the operation is to be done due to an acute obstetric emergency resulting in endangering to lives of mother and child. ${ }^{4}$ Proportion of $\mathrm{CS}$ to the total births is considered as one of the important indicators of emergency obstetric care (World Health Organization, 2009). A figure below 5 per cent implies that a substantial proportion of women do not have access to surgical obstetric care; on the other hand, a rate higher than 15 per cent indicates over utilization of the procedure for other than life saving reasons (WHO, 1985; WHO, 1993).

As per WHO guidelines there is no justification for any region to have a caesarean section rate of higher than 10 $15 \% .^{5}$ In recent years the rate has risen to a record level of $46 \%$ in China and $25 \%$ or above in many Asian and European countries, Latin America and USA and some evidence finds that a higher rate may result in better outcome. ${ }^{6,7}$ More than 45 countries globally have Csection rates less than $7.5 \%$ while more than 50 have rates greater than $27 \%$. There are efforts to both improve access to and reduce the use of $\mathrm{C}$-section. ${ }^{7}$ Increased caesarean section rate in the developed countries is mainly due to fear of litigation, health insurance system, caesarean section by choice, increased use of electronic fetal cardiac monitoring and increased proportion of breech deliveries by caesarean section. In developing countries, the reasons for increasing caesarean section rate are different. Poor socioeconomic conditions, low literacy level, lack of primary health care and low threshold of some doctors for caesarean section are the main reasons.

Aims and objective of present study was to compare the rate of cesarean section over the years, to analyze the rate of primary and repeat cesarean section, to find the common indications of primary cesarean section, to see if there is change in the trend of indications for emergency and elective primary cesarean section and to compare the indications of emergency and elective, repeat cesarean sections over 5 years.

\section{METHODS}

This is a retrospective analysis of all the patients who underwent Cesarean section in the department of Obstetrics and Gynecology at L. N. Medical College from $1^{\text {st }}$ January 2012 to $31^{\text {st }}$ December 2016.

\section{Inclusion criteria}

All patients who underwent cesarean whether elective or emergency and whether booked or unbooked patient.

\section{Exclusion criteria}

Gestational age less than 28 weeks.

Year-wise data of cesarean section and vaginal deliveries was recorded and the rate of cesarean section in each year was calculated.

Total caesarean section rate is total number of deliveries by caesarean section divided by total number of births multiplied by 100 . Primary caesarean section is a caesarean section to a woman who has had no previous caesarean section. The rate of primary and repeated cesarean section was also calculated year-wise. The number of emergency and elective cesarean section were also noted year-wise. The indications for Primary and Repeat CS were also recorded and also the Emergency and Elective indications were recorded separately.

Data was collected from labour register and operation register and the results were summarized in percentages and proportions. Statistical associations were done using Chi square test wherever required with p 0.05 considered as statistically significant.

\section{RESULTS}

The majority of patients who underwent cesarean were in the age group of 15-25 yrs all throughout five years (Table 1) and were multigravidas except in 2016 in which the majority were primigravidas (Table 2 ).

Table 1: Age of the patient.

\begin{tabular}{|llllll|} 
& 2012 & 2013 & 2014 & 2015 & 2016 \\
\hline $15-25 y r s$ & 71 & 80 & 80 & 117 & 225 \\
\hline $26-35 y r s$ & 84 & 50 & 79 & 111 & 219 \\
\hline $36-45 y r s$ & 2 & 2 & 3 & 4 & 8 \\
\hline
\end{tabular}

Table 2: Parity of the patient.

\begin{tabular}{|llllll|}
\hline & 2012 & 2013 & 2014 & 2015 & 2016 \\
\hline Primigravida & 70 & 63 & 77 & 108 & 237 \\
\hline Multigravida & 82 & 73 & 79 & 120 & 213 \\
\hline $\begin{array}{l}\text { Grand } \\
\text { multigravida }\end{array}$ & 5 & 4 & 6 & 5 & 2 \\
\hline
\end{tabular}

Table 3: Booked/Unbooked.

\begin{tabular}{|llllll|}
\hline & 2012 & 2013 & 2014 & 2015 & 2016 \\
\hline Booked & $102(64.9 \%)$ & $92(65.7 \%)$ & $101(62.4 \%)$ & $135(58.2 \%)$ & $252(55.8 \%)$ \\
\hline Unbooked & $55(35.1 \%)$ & $48(34.3 \%)$ & $61(37.6 \%)$ & $97(41.8 \%)$ & $200(44.2 \%)$ \\
\hline Total cesarean & 157 & 140 & 162 & 232 & 452 \\
\hline
\end{tabular}


The percentage of unbooked patients has increased through five years from $35.1 \%$ in 2012 to $44.2 \%$ in 2016 which is due to more number of cases referred from periphery to our tertiary centre (Table 3). In present study, the cesarean rate in 2012 was $43.85 \%$ which has increased to $55.11 \%$ in 2015 and $48.18 \%$ in 2016 . The average CS rate was $49.2 \%$ (Table 4 ).

There is increase in the number of primary cesarean cases over the years. In $201261.8 \%$ were primary cesarean which increased to $65 \%$ in 2013 and to $68.4 \%$ in 2016 (Table 5) which suggests the increase in primary cesarean cases.

The percentage of Elective CS has increased in last five years from $10.2 \%$ in 2012 to $23.6 \%$ in 2016 which included both Elective Primary CS and Elective Repeat $\mathrm{CS}$ and is mainly due to the drastic increase in Elective Repeat CS through five years as mentioned in latter tables (Table 6).

Table 4: Rate of cesarean section year-wise in numbers and \%.

\begin{tabular}{|llll|}
\hline & $\begin{array}{l}\text { Total } \\
\text { deliveries }\end{array}$ & $\begin{array}{l}\text { No. of cesarean } \\
\text { deliveries }\end{array}$ & $\begin{array}{l}\text { Cesarean } \\
\text { rate }(\%)\end{array}$ \\
\hline 2012 & 358 & 157 & 43.85 \\
\hline 2013 & 311 & 140 & 45.01 \\
\hline 2014 & 295 & 162 & 54.91 \\
\hline 2015 & 421 & 232 & 55.11 \\
\hline 2016 & 938 & 452 & 48.18 \\
\hline Total & 2323 & 1143 & 49.20 \\
\hline
\end{tabular}

Table 5: Incidence of primary cesarean section and repeat cesarean section.

\begin{tabular}{|llllll|}
\hline Total CS & 2012 & 2013 & 2014 & 2015 & 2016 \\
\hline \multirow{2}{*}{ Primary CS } & 157 & 140 & 162 & 232 & 452 \\
& $97(61.8 \%)$ & $91(65 \%)$ & $108(66.7 \%)$ & $153(65.9 \%)$ & $309(68.4 \%)$ \\
& $\mathrm{Em}=89$ & $\mathrm{Em}=88$ & $\mathrm{Em}=93$ & $\mathrm{Em}=127$ & $\mathrm{Em=264}$ \\
& $\mathrm{El}=8$ & $\mathrm{El}=3$ & $\mathrm{El}=15$ & $\mathrm{El}=26$ & $\mathrm{El}=45$ \\
Repeat CS & $60(38.2 \%)$ & $49(35 \%)$ & $54(33.3 \%)$ & $79(34.1 \%)$ & $143(31.6 \%)$ \\
& $\mathrm{Em}=52$ & $\mathrm{Em}=41$ & $\mathrm{Em}=33$ & $\mathrm{Em}=38$ & $\mathrm{Em=81}$ \\
& $\mathrm{El}=8$ & $\mathrm{El}=8$ & $\mathrm{El}=21$ & $\mathrm{El}=41$ & $\mathrm{El}=62$ \\
\hline
\end{tabular}

Table 6: Incidence of emergency and elective CS.

\begin{tabular}{|llllll|}
\hline & 2012 & 2013 & 2014 & 2015 & 2016 \\
\hline Emergency & $141(89.8 \%)$ & $129(92.2 \%)$ & $126(77.8 \%)$ & $165(71.1 \%)$ & $345(76.3 \%)$ \\
\hline Elective & $16(10.2 \%)$ & $11(7.8 \%)$ & $36(22.2 \%)$ & $67(28.9 \%)$ & $107(23.6 \%)$ \\
\hline Total & 157 & 140 & 162 & 232 & 452 \\
\hline
\end{tabular}

Table 7: Indications of primary cesarean section.

\begin{tabular}{|llllll|}
\hline Fetal distress & 2012 & 2013 & 2014 & 2015 & 2016 \\
\hline CPD & $36(37.1 \%)$ & $40(43.9 \%)$ & $38(35.2 \%)$ & $57(37.2 \%)$ & $106(34.3 \%)$ \\
\hline NPOL & $19(19.6 \%)$ & $16(17.6 \%)$ & $12(11.1 \%)$ & $23(15.2 \%)$ & $56(18.1 \%)$ \\
\hline Failed induction & $16(16.5 \%)$ & $8(8.7 \%)$ & $9(8.3 \%)$ & $12(7.8 \%)$ & $39(12.6 \%)$ \\
\hline Oligohydraminos with IUGR & $8(8.2 \%)$ & $4(4.4 \%)$ & $4(3.7 \%)$ & $8(5.2 \%)$ & $13(4.2 \%)$ \\
\hline Malpresentation & $2(2.1 \%)$ & $2(2.2 \%)$ & $16(14.8 \%)$ & $15(9.8 \%)$ & $31(10.1 \%)$ \\
\hline Severe pre-eclampsia/Eclampsia & $7(7.2 \%)$ & $11(12.1 \%)$ & $8(7.4 \%)$ & $18(11.8 \%)$ & $30(9.7 \%)$ \\
\hline Multiple pregnancy & $1(1.0 \%)$ & $4(4.4 \%)$ & $5(4.6 \%)$ & $8(5.2 \%)$ & $7(2.3 \%)$ \\
\hline Precious pregnancy & - & - & $2(1.9 \%)$ & $4(2.6 \%)$ & $9(2.9 \%)$ \\
\hline APH & $4(4.1 \%)$ & $1(1.1 \%)$ & $3(2.8 \%)$ & $2(1.3 \%)$ & $10(3.2 \%)$ \\
\hline Obstructed labour & $2(2.1 \%)$ & $3(3.3 \%)$ & $8(7.4 \%)$ & $2(1.3 \% 0$ & $4(1.3 \%)$ \\
\hline Total & $2(2.1 \%)$ & $2(2.2 \%)$ & $3(2.8 \%)$ & $4(2.6 \%)$ & $4(1.3 \%)$ \\
\hline
\end{tabular}

The first and second major indication of Primary CS over the years remained the same i.e. fetal distress and CPD. Oligohydraminos and IUGR contributed as indication in $14.8 \%$ patients in $2014,9.8 \%$ in 2015 and $10.1 \%$ patients in 2016 whereas it was not a major indication in 2012
(3.1\%) and $2013(2.2 \%)$ (Table 7). Other major contributing indications were non-progress of labour, failed induction. Malpresentation also contributed as the fifth major indication for primary CS in 2012, 2014 and 2016 and was the third major indicaton in 2013 and 2015 
(Table 7). On comparing the emergency and elective primary CS over the years, we concluded that the elective primary CS cases increased from $8.2 \%$ in 2012 to $14.6 \%$ in 2016 (Table 8).

Table 8: Incidence of Emergency and Elective Primary CS.

\begin{tabular}{|llllll|}
\hline & 2012 & 2013 & 2014 & 2015 & 2016 \\
\hline Emergency & $89(91.7 \%)$ & $88(96.7 \%)$ & $93(86.1 \%)$ & $127(83.0 \%)$ & $264(85.4 \%)$ \\
\hline Elective & $8(8.2 \%)$ & $3(3.3 \%)$ & $15(13.9 \%)$ & $26(17 \%)$ & $45(14.6 \%)$ \\
\hline Total & 97 & 91 & 108 & 153 & 309 \\
\hline
\end{tabular}

Table 9: Comparing indications of primary emergency cesarean sections.

\begin{tabular}{|llllll|}
\hline Indication & 2012 & 2013 & 2014 & 2015 & 2016 \\
\hline Fetal distress & $36(40.5 \%)$ & $40(45.5 \%)$ & $38(40.9 \%)$ & $57(44.9 \%)$ & $106(40.2 \%)$ \\
\hline CPD & $14(15.7 \%)$ & $14(15.9 \%)$ & $9(9.7 \%)$ & $11(8.7 \%)$ & $47(17.8 \%)$ \\
\hline NPOL & $16(17.9 \%)$ & $8(9.1 \%)$ & $9(9.7 \%)$ & $12(9.5 \%)$ & $39(14.8 \%)$ \\
\hline Failed induction & $8(8.9 \%)$ & $4(4.5 \%)$ & $4(4.3 \%)$ & $8(6.3 \%)$ & $13(4.9 \%)$ \\
\hline Severe oligohydraminos & $2(2.2 \%)$ & $2(2.3 \%)$ & $13(13.9 \%)$ & $14(11 \%)$ & $20(7.6 \%)$ \\
\hline Malpresentation & $7(7.9 \%)$ & $11(12.5 \%)$ & $3(3.2 \%)$ & $10(7.9 \%)$ & $20(7.6 \%)$ \\
\hline Severe pre-eclampsia/eclampsia & - & $4(4.5 \%)$ & $5(5.4 \%)$ & $8(6.3 \%)$ & $7(2.7 \%)$ \\
\hline Obstructed labour & $2(2.2 \%)$ & $2(2.3 \%)$ & $3(3.2 \%)$ & $4(3.1 \%)$ & $4(1.5 \%)$ \\
\hline Precious pregnancy & $3(3.4 \%)$ & - & - & - & $4(1.5 \%)$ \\
\hline APH & $1(1.1 \%)$ & $3(3.4 \%)$ & $7(7.5 \%)$ & $2(1.6 \%)$ & $2(0.8 \%)$ \\
\hline Multiple pregnancy & - & - & $2(2.2 \%)$ & $1(0.8 \%)$ & $2(0.8 \%)$ \\
\hline Total & 89 & 88 & 93 & 127 & 264 \\
\hline
\end{tabular}

On comparing the indications for emergency primary CS, fetal distress was the most common indication in 2012 and also in 2016. Severe pre-eclampsia has also emerged as the indication for emergency primary CS in 2016 which may be due to the increasing medical disorders in the patients. Multiple pregnancy and precious pregnancies have also contributed as the indications in 2016 due to increase number of pregnancies by IVF (Table 9).

Table 10: Comparing indications of primary elective cesarean sections.

\begin{tabular}{|llllll|}
\hline Indication & 2012 & 2013 & 2014 & 2015 & 2016 \\
\hline Malpresentation & - & - & 5 & 8 & 10 \\
\hline CPD & 5 & 2 & 3 & 12 & 9 \\
\hline $\begin{array}{l}\text { Precious } \\
\text { pregnancy }\end{array}$ & 1 & 1 & 3 & 2 & 6 \\
$\begin{array}{l}\text { Placenta previa } \\
\text { (APH) }\end{array}$ & 2 & - & 1 & - & 2 \\
\hline $\begin{array}{l}\text { IUGR with } \\
\text { oligo }\end{array}$ & - & - & 3 & 1 & 11 \\
$\begin{array}{l}\text { Multiple } \\
\text { pregnancy }\end{array}$ & - & - & - & 3 & 7 \\
\hline Total & 8 & 3 & 15 & 26 & 45 \\
\hline
\end{tabular}

The major indications for elective primary CS in 2016 were Oligohydraminos, malpresentation, CPD, multiple pregnancy and precious pregnancy (Table 10).
The main indication for repeat Cesarean section in 2012 was scar tenderness $(21.7 \%)$ which shifted to previous 2 CS $(22.4 \%)$ in 2013 , previous CS (31.6\% and $34.2 \%)$ in 2014 and 2015 respectively and to scar tenderness (21\%) again in 2016 (Table 11).

Previous CS and Previous 2 CS altogether contributed as indication for Repeat CS in $6.7 \%$ in $2012,32.6 \%$ in 2013, $41 \%$ in 2104 and $45.6 \%$ in 2015.This is because of the decreasing trial of labour in cases of Previous CS.

As seen in Table 12 the Elective Repeat CS in 2012 were only $13.3 \%$ which increased to $16.3 \%$ in $2013,38.9 \%$ in $2014,51.9 \%$ in 2015 and $43.4 \%$ in 2016 .

The number of elective CS in previous CS cases has increased due to better outcome of mother and baby both and also due to the fear of litigations. Altogether there is raise in elective primary and repeat $\mathrm{CS}$.

Emergency CS in cases of Previous CS was done in majority due to scar tenderness and it was the main indication all throughout five years (Table 13).

Both previous CS and Previous 2 CS contributed as the main indication for elective repeat cesarean cases all throughout five years (Table 14). The increasing trend of elective CS in previous CS cases is due to the decreasing trend of trial of labour in previous CS cases. 
Table 11: Indications of repeat cesarean section.

\begin{tabular}{|llllll|}
\hline Scar tenderness & 2012 & 2013 & 2014 & 2015 & 2016 \\
\hline Fetal distress & $13(21.7 \%)$ & $9(18.4 \%)$ & $11(20.4 \%)$ & $20(25.3 \%)$ & $30(21 \%)$ \\
\hline Malpresentation & $7(11.7 \%)$ & $8(16.3 \%)$ & $3(5.5 \%)$ & $5(6.3 \%)$ & $11(7.7 \%)$ \\
\hline Severe oligo & $8(13.3 \%)$ & $1(2.0 \%)$ & $2(3.7 \%)$ & - & $16(11.2 \%)$ \\
\hline Severe pre-eclampsia/Eclampsia & $8(13.3 \%)$ & $2(4.1 \%)$ & $3(5.5 \%)$ & $10(12.6 \%)$ & $12(8.4 \%)$ \\
\hline Postdated & $2(3.3 \%)$ & - & $3(5.5 \%)$ & $2(2.5 \%)$ & $1(0.7 \%)$ \\
\hline CPD & - & $2(4.1 \%)$ & $3(5.5 \%)$ & $1(1.3 \%)$ & $1(0.7 \%)$ \\
\hline PROM & $7(11.7 \%)$ & $6(12.2 \%)$ & - & $3(3.8 \%)$ & $12(8.4 \%)$ \\
\hline Precious pregnancy & $6(10 \%)$ & $1(2.1 \%)$ & $6(11.1 \%)$ & $1(1.3 \%)$ & $8(5.6 \%)$ \\
\hline Previous CS & - & $2(4.1 \%)$ & - & $1(1.3 \%)$ & $12(8.4 \%)$ \\
\hline Previous 2CS & - & $5(10.2 \%)$ & $17(31.6 \%)$ & $27(34.2 \%)$ & $20(13.9 \%)$ \\
\hline $\begin{array}{l}\text { Others } \\
\text { (Cord around neck, APH) }\end{array}$ & $4(6.7 \%)$ & $11(22.4 \%)$ & $5(9.4 \%)$ & $9(11.4 \%)$ & $18(12.6 \%)$ \\
\hline Total & $5(8.3 \%)$ & $2(4.1 \%)$ & $1(1.8 \%)$ & - & $2(1.4 \%)$ \\
\hline
\end{tabular}

Table 12: Incidence of emergency and elective repeat CS.

\begin{tabular}{|llllll|}
\hline & 2012 & 2013 & 2014 & 2015 & 2016 \\
\hline Emergency & $52(86.7 \%)$ & $41(83.7 \%)$ & $33(61.1 \%)$ & $38(48.1 \%)$ & $81(56.6 \%)$ \\
\hline Elective & $8(13.3 \%)$ & $8(16.3 \%)$ & $21(38.9 \%)$ & $41(51.9 \%)$ & $62(43.4 \%)$ \\
\hline Total & 60 & 49 & 54 & 79 & 143 \\
\hline
\end{tabular}

Table 13: Indications of emergency repeat cesarean section over the years.

\begin{tabular}{|llllll|}
\hline & 2012 & 2013 & 2014 & 2015 & 2016 \\
\hline Scar tenderness & $13(25 \%)$ & $9(21.9 \%)$ & $11(33.3 \%)$ & $20(52.6 \%)$ & $30(37.0 \%)$ \\
\hline Fetal distress & $7(13.5 \%)$ & $8(19.5 \%)$ & $3(9.1 \%)$ & $5(13.2 \%)$ & $11(13.6 \%)$ \\
\hline Malpresentation & $7(13.55)$ & $1(2.4 \%)$ & - & - & $6(7.4 \%)$ \\
\hline Severe oligohydraminos & $7(13.5 \%)$ & $2(4.9 \%)$ & - & $5(13.2 \%)$ & $10(12.3 \%)$ \\
\hline Severe pre-eclampsia/Eclampsia & $2(3.9 \%)$ & - & $3(9.1 \%)$ & $2(5.3 \%)$ & - \\
\hline PROM & $6(11.5 \%)$ & $1(2.4 \%)$ & $6(18.2 \%)$ & $1(2.6 \%)$ & $8(9.9 \%)$ \\
\hline CPD & $5(9.6 \%)$ & $5(12.2 \%)$ & - & - & $2(2.5 \%)$ \\
\hline Precious pregnancy & $1(1.9 \%)$ & $2(4.9 \%)$ & - & - & $6(7.4 \%)$ \\
\hline Previous CS & - & $4(9.8 \%)$ & $9(27.3 \%)$ & $4(10.5 \%)$ & $6(7.4 \%)$ \\
\hline Previous 2CS & - & $7(17.1 \%)$ & - & $1(2.6 \%)$ & $2(2.5 \%)$ \\
\hline $\begin{array}{l}\text { Others } \\
\text { (APH, Multiple preg, RHD) }\end{array}$ & $4(7.7 \%)$ & $2(4.9 \%)$ & $1(3.0 \%)$ & - & - \\
\hline Total & 52 & 41 & 33 & 38 & 81 \\
\hline
\end{tabular}

Table 14: Indications of elective repeat cesarean section over the years.

\begin{tabular}{|llllll|}
\hline Postdated & 2012 & 2013 & 2014 & 2015 & 2016 \\
\hline Oligohydraminos with IUGR & - & $2(25 \%)$ & $3(14.3 \%)$ & $1(2.4 \%)$ & $1(1.6 \%)$ \\
\hline CPD & $1(12.5 \%)$ & - & $3(14.3 \%)$ & $5(12.2 \%)$ & $2(3.2 \%)$ \\
\hline Malpresentation & $2(25 \% 0$ & $1(12.5 \%)$ & - & $3(7.3 \%)$ & $10(16.1 \%)$ \\
\hline Severe pre-eclampsia/eclampsia & $1(12.5 \%)$ & - & $2(9.5 \%)$ & - & $10(16.1 \%)$ \\
\hline Precious pregnancy & - & - & - & - & $1(1.6 \%)$ \\
\hline Previous CS & - & - & - & $1(2.4 \% 0$ & $6(9.7 \%)$ \\
\hline Previous 2CS & - & $1(12.5 \%)$ & $8(38.1 \%)$ & $23(56.1 \%)$ & $14(22.6 \%)$ \\
\hline $\begin{array}{l}\text { Others } \\
\text { (Hydrocephalus, RHD) }\end{array}$ & $4(50 \%)$ & $4(50 \%)$ & $5(23.8 \%)$ & $8(19.5 \%)$ & $16(25.9 \%)$ \\
\hline Total & - & - & - & - & $2(3.2 \%)$ \\
\hline & 8 & 8 & 21 & 41 & 62 \\
\hline
\end{tabular}




\section{DISCUSSION}

According to NFHS 4 (National Family Health Survey) in 2015-16, births delivered by Cesarean section in Madhya Pradesh is $8.6 \%$ (total) which includes $19.1 \%$ in urban and $5.1 \%$ in rural area. In 2005-2006 NFHS 3 survey this rate was $3.5 \%$ only which by itself indicates the rise in rate of Cesarean section over the decade in Madhya Pradesh. ${ }^{8}$

Whereas births in private health facility delivered by cesarean section in Madhya Pradesh was on average $40.8 \%$ according to NFHS 4 (2015-2016) which shows very much increased rate of cesarean section in private set ups which may be the contributing factor in the increase of CS rates. ${ }^{8}$ In present study the CS rate in 2015-16 was $50.5 \%$ which is high due to increase number of cases referred from periphery.

Bhardwaj $\mathrm{M}$ et al reported from a medical college of Central India as the overall rate of CS in their institution, over four years (2008-2011) was $48.1 \% .^{9}$ In present study the average Cesarean rate over 5 years (2012-2016) was $49.2 \%$ which corresponds with their study.

The rising trend was also noted by Gjong et al of Tirane in their study. ${ }^{10}$ In their study they viewed a growing trend of births by CS by $8.44 \%$ in 1982 to $24.19 \%$ in 2000 and increased to $32.9 \%$ in 2013 . Thus, the problem of rising trend of CS is not only in India but is present worldwide.

In a study by Divyamol $\mathrm{N}$ et al the rate of caesarean section was $37.7 \% .^{11}$ The major indications were previous caesarean sections $(40.44 \%)$, failure of labor to progress $(22.47 \%)$ and fetal distress $(14.6 \%)$. In the study by Bhardwaj et al the leading indication for caesarean section was fetal distress $(35 \%)$ and the other major indications were previous caesarean delivery (26\%), Cephalo Pelvic Disproportion (10.4\%), Malposition/malpresentation $(8.2 \%)$ and others. ${ }^{9}$ In present study also after Previous CS, fetal distress was the main indication of Cesarean section.

In a study in a tertiary care centre of Rajasthan by Ranjana A et al in 2015, emergency CS rate was $57.5 \%$ and elective CS rate was $42.5 \% .^{12}$ In present study $71.1 \%$ were emergency CS and $28.9 \%$ were elective CS. Elective primary CS were less $17 \%$ whereas the Elective repeat CS rate was very high $51.9 \%$ which suggests that main indication for elective CS was previous CS.

Kumar MV et al in their study in 2016 found that among emergency caesarean section, the main indications for caesarean was failed induction. ${ }^{13}$ In present study the main indication for emergency Primary CS was fetal distress followed by CPD and then Non progress of labour. Jawa et al also studied that Fetal distress, previous LSCS, NPOL (including failed induction) and
Hypertensive disorders of pregnancy (HDP) were the leading indications in the emergency $\mathrm{CS} .{ }^{14}$

Among elective caesarean section in the study of Kumar $\mathrm{MV}$ et al most common indication was previous caesarean section, followed by cephalopelvic disproportion. ${ }^{13}$ In present study also the main indication for elective CS was previous CS but there is rise in elective Primary CS from 2012 to 2016 and the main indication in 2016 was IUGR with oligohydraminos followed by malpresentation. In a study by Verma et al also the commonest indication for elective cesarean section was previous cesarean section $(42 \%)$ followed by previous 2LSCS (15\%), primi breech (15\%), and CPD $(14 \%) .^{15}$

RCOG recommended that all women previously delivered by one lower segment CS should be offered an opportunity to labor during their next pregnancy by promoting a trial of scar or of labor but due to fear of scar rupture and fear of litigations trial of labour after Cesarean is a vanishing practice now-a-days. ${ }^{16}$

\section{CONCLUSION}

There is increase in the rate of Cesarean section not only in India but globally also. The leading indications of primary CS throughout five years remains same which is fetal distress, CPD and Non-progress of labour. The overall main indication for Cesarean section is Previous CS and thus decreasing the Primary CS would help in decreasing the rate of $\mathrm{CS}$. The major indication for Primary CS was fetal distress which should be further confirmed by fetal scalp $\mathrm{pH}$ findings and thus may help in reducing the rate of Primary CS. The increase in cases of elective primary CS need to be reduced. The increase in the elective section for previous CS could be decreased by providing legal cover to the doctors so that more cases of previous sections will be given the trial of labour for vaginal delivery.

Funding: No funding sources Conflict of interest: None declared

Ethical approval: The study was approved by the Institutional Ethics Committee

\section{REFERENCES}

1. Pregnancy Labor and Birth. Women's Health. September 27, 2010. Available at https://www.womenshealth.gov/pregnancy/childbirth -and-beyond/labor-and-birth. Accessed on 31 July 2016.

2. ACOG. Safe Prevention of the Primary Cesarean Delivery. American Congress of Obstetricians and Gynecologists and the Society for Maternal-Fetal Medicine. March 2014. Available at http://www.acog.org/Resources-And-

Publications/Obstetric-Care-Consensus-Series/Safe- 
Prevention-of-the-Primary-Cesarean-Delivery

Accessed on 20 February 2014.

3. Betran AP, Torloni MR, Zhang JJ, Gülmezoglu AM. WHO Statement on caesarean section rates. BJOG: Int J Obstet Gynaecol. 2015 Jul 1.

4. Mukherjee SN. Rising cesarean section rate. J Obstet Gynecol India. 2006;56(4):298-300.

5. World Health Organization. Monitoring emergency obstetric care a handbook. 2009. Available at http:///www.who.int/reproductivehealth/public ations/monitoring/.../en/

6. Caesarean Section Rate around globe at epidemic level. 2011 Jan 12 Available at Ap/ msnbc.com. Accessed on 21 Feb 2010.

7. Molina G, Weiser TG, Lipsitz SR, Esquivel MM, Uribe-Leitz T, Azad T, et al. Relationship Between Cesarean Delivery Rate and Maternal and Neonatal Mortality. JAMA. 2015;314(21):2263-70.

8. National Family Health Survey-4 2015 -16, Stae fact sheet Madhya Pradesh. Available at http://rchiips.org/NFHS/pdf/NFHS4/MP_FactSheet.p df

9. Bharadwaj M, Modi J. A four-year audit of deliveries by Caeserean section at a medical college hospital in Central India. Int J Reprod Contracept Obstet Gynecol. 2015;4:1775-82.

10. Gjonej R, Poloska A, Keta M, Delija Z. The reasons of rising trend of Cesarean section rate year after year. A retrospective study. Int J Nur Midwifer. 2015;7(1):9-15.

11. Divyamol N, Raphael L, Koshy N. Caesarean section rate and its determinants in a rural area of South
India. Int $\mathbf{J}$ Community Med Public Health 2016;3:2836-40.

12. Atal R, Rathore SB. Determinates of Caesarean section in tertiary care hospital. Sch J App Med Sci. 2016;4(6D):2163-6.

13. Maktha VK, Ghatam A, Padamata H, Ravulakol A. Prevalence and factors associated with caesarean section: a community based cross sectional study in rural parts of Rangareddy district, Telangana, India. 2016;3(8):2054-7.

14. Jawa A, Garg S, Tater A, Sharma U. Indications and rates of lower segment caesarean section at tertiary care hospital-an analytical study. Int $\mathrm{J}$ Reprod Contracept Obstet Gynecol. 2016 Oct;5(10):3466-9.

15. Verma S, Saini J, Sehra R, Nagaraj N. A clinical study of rate and indications of cesarean section, maternal and fetal outcomes at tertiary care center in north western Rajasthan. Int J Reprod Contracept Obstet Gynecol 2016;5:2791-4.

16. Thomas J, Parenajothy S. Royal College of Obstetricians and Gynecologists Clinical Effectiveness Support Unit. The National Sentinel Cesarean Section Audit Report. London. RCOG Press. 2001.

Cite this article as: Patil $\mathrm{P}$, Bhardwaj M, Sharma P, Chandrakar G. Changing trends in indication of cesarean section in a tertiary care centre of Central India. Int J Reprod Contracept Obstet Gynecol 2017;6:2829-35. 